\title{
Predation risk, cover type, and group size in European rabbits in Doñana (SW Spain)
}

\author{
Rafael VILLAFUERTE and Sacramento MORENO
}

\begin{abstract}
Villafuerte R. and Moreno S. 1997. Predation risk, cover type, and group size in European rabbits in Doñana (SW Spain). Acta Theriologica 42: 225-230.

As European rabbits Oryctolagus cuniculus (Linnaeus, 1758) in SW Spain face high predation pressure, some antipredator tactics are expected. We examined rabbit group size in relation to the safety of the cover (sparse or dense), and the proximity to shrub cover. Stem density influenced the distance rabbits ventured from shrub; rabbits ventured greater distances when stem density in cover was higher. Rabbit group size was related to the distance to cover; solitary animals remained closer to protective cover, whereas rabbits in groups ( $\geq 3$ animals) foraged further from cover. These results are consistent with the hypothesis that the formation of rabbit groups is related to defense against predation, and that group size is influenced by risk of perception.
\end{abstract}

Estación Biológica de Doñana, CSIC. Apdo. 1056, Sevilla 41080, Spain; e-mail: villafuerte@cica.es

Key words: Oryctolagus cuniculus, predation risk, group size, habitat structure, log-linear models

\section{Introduction}

The European rabbit Oryctolagus cuniculus (Linnaeus, 1758) is native to Spain (Zeuner 1963). In many regions where they occur, they use proximity to cover as an antipredator strategy (Jaksić et al. 1979, Moreno et al. 1996). However, diferences in predator avoidance tactics have been observed between European rabbits that have been introduced to new regions and endemic populations (Jaksić and Soriguer 1981). In regions where the rabbit is not native (eg Australia and Chile), they may reach high densities in open habitats because of a lack of effective predators (Jaksić et al. 1979). However, Simonetti and Fuentes (1982) have shown that juvenile rabbits in Chile tend to use areas closer to shrub, which is a behaviour similar to adult rabbits in Spain.

Rabbits must forage away from cover to obtain food, which results in a high risk of predation. It has been shown that rabbits in Spain forage in the open at night, because they are less at risk, while rabbits stay in cover in daylight as it is safer (Moreno et al. 1996). However, by living in groups, rabbits may reduce this risk because a foraging group can detect an approaching predator sooner 
(Bertram 1978), and each member of a group is less at risk of being singled out during an attack (Vine 1971).

If the distance of an individual rabbit from a refuge (eg shrub cover) can be considered as an index of risk (Jaksić et al. 1979, Jaksić and Soriguer 1981), and if individuals experience lower predation risk when in a group, then we can predict that single rabbits would stay closer to cover whereas groups of rabbits would be able to forage farther from cover. Nevertheless, most authors have used "cover" as a broad term which includes many types of refuge. As the perception of risk for a prey would be very different depending on the degree of obstruction that the cover presents to approaching predators, and the safety of the refuge it provides (eg Lazarus and Symonds 1992), the relationship between cover and predation risk is more complicated than it appears and needs further investigation.

In this paper we test both, the relationships between rabbit group size and distance to cover, and the rabbits' perception of risk in two different shrub types (dense and sparse), in a rabbit population in southwestern Spain.

\section{Methods}

The study was conducted in Doñana National Park (southwestern Spain, ca $37^{\circ} 10^{\prime} \mathrm{N}, 6^{\circ} 23^{\prime} \mathrm{W}$ ) that covers $550 \mathrm{~km}^{2}$ on the west bank of the mouth of the Guadalquivir River. The climate is Mediterranean, with hot dry summers and mild rainy winters. Three main biotopes exist: marshes, shrubland, and dunes, and rabbits are especially abundant in the shrub-marshland ecotone where they dig warrens in the shrub, and feed in the marsh (Beltrán 1991, Moreno and Villafuerte 1995, Moreno et al. 1996). The marshland includes open grasslands with higher quality and more abundant forage than the shrubland (Lazo 1992).

Two shrub types are easily distinguishable by height and degree of visual obstruction: (a) sparse-shrubland, composed mainly of Cistus spp. and Halimium spp. and (b) dense-shrubland, conposed mainly of Erica spp. (Allier et al. 1974). Mean cover percentages for each shrub type are very different: $91 \%$ for dense and 50\% for sparse shrub (Kufner and Moreno 1989). No differences existed in biomass or composition of grasses in the proximity of either shrub types (Lazo 1992).

In Spain, rabbits are a major prey of 29 predators (Jaksić and Soriguer 1981). At Doñana, at least 16 species prey upon rabbits (Moreno et al. 1996). Four carnivores: Iberian lynx Lynx pardinus, wildcat Felis silvestris, red fox Vulpes vulpes, and mongoose Herpestes ichneumon; and five birds of prey: red kite Milvus milvus, black kite M. migrans, imperial eagle Aquila adalberti, booted eagle Hieraetus pennatus, and marsh harrier Circus aeroginosus, include rabbits as more than $15 \%$ of their $\operatorname{diet}$ (M. Delibes, pers. com.).

Observations of single individuals and rabbits in groups were conducted from a vehicle along a permanent census course (about $5 \mathrm{~km}$ long) in the grasslands just at the border of the shrublands, where the two cover types intermingle but are clearly delimited, so rabbits were easily assirned to each type of shrub. Monthly data were collected for three consecutive days one hour before duik from January 1989 to December 1990. Warren density is low in the shrub along this transect because they are situated in sandy areas within the shrub. As a result, nearly all rabbits censused were adults, because young rabbits do not travel long distances from warrens (Kolb 1991).

Rabbits were considered paired or in a group when the distance between them did not exceed $10 \mathrm{~m}$. If any animal was further away when first sighted but at less than $25 \mathrm{~m}$ from its aearest neighbour, it was not included. Only individuals or groups at least $25 \mathrm{~m}$ from each other were considered independent. Thus, rabbits were assigned to three group sizes (GS): solitary, pairs, or 
groups ( $\geq 3$ rabbits). Distance of a rabbit from cover (DC) and cover type (CT), ie dense or sparse, were also recorded. Distance to shrub for a group was assigned as the mean distance of all the individuals in the group, assigned to 3 distance categories: short $(0-2 \mathrm{~m})$, medium $(2-5 \mathrm{~m})$, and long $(>5 \mathrm{~m})$.

Using the frequency of sighting of rabbit groups, a three dimensional table $(\mathrm{GS} \times \mathrm{CT} \times \mathrm{DC})$ was built. Data analysis was done using BMDP-4F (Dixon 1983). Partial and marginal associations among these variables were tested using $G$-tests. A log-linear model was built considering only those interactions showing both types of association as being significant, and the expected values generated by the model (lambda) were compared with the table of observed values by a $G$-test (Heisey 1985). Standardized values of the log-linear parameters of the model were used to test the deviations of predicted frequencies from randomness (Edwards 1989).

\section{Results}

In total, 2331 rabbit 'groups' were observed (Table 1): 1895 solitary individuals, 337 pairs and 99 rabbit groups (with mean size 4 , range $3-20$ ). We found significant associations between group size and the distance to cover (partial association: $G^{2}=11.26, \mathrm{df}=2, p<0.01$; marginal association: $G^{2}=11.77, \mathrm{df}=2$, $p<0.01$ ), and between shrub type and distance (partial association: $G^{2}=24.37$, $\mathrm{df}=4, p<0.001$; marginal association: $\left.G^{2}=24.88, \mathrm{df}=4, p<0.001\right)$. No relation was found between the size of a rabbit group and the shrub type (partial association: $G^{2}=4.55, \mathrm{df}=2, p>0.05$; marginal association: $G^{2}=5.07, \mathrm{df}=2$, $p>0.05$ ). Second order interactions among variables were not significant. The log-linear model, taking into consideration only those significant interactions $(\mathrm{GS} \times \mathrm{DC}, \mathrm{CT} \times \mathrm{DC})$, predicted a table of values that did not differ from the observed distribution $\left(G^{2}=10.72, \mathrm{df}=6, p>0.05\right)$.

The analysis of the log-linear parameters showed that solitary rabbits were found more frequently closer to and less frequently further from shrub than

Table 1. Number of rabbit groups observed, classified according to their distance to cover and shrub type.

\begin{tabular}{llccc}
\hline \multirow{2}{*}{ Group size } & Cover type & \multicolumn{3}{c}{ Distance to cover } \\
\cline { 3 - 5 } & & Short $(0-2 \mathrm{~m})$ & Medium $(2-5 \mathrm{~m})$ & Long $(>5 \mathrm{~m})$ \\
\hline \multirow{2}{*}{ Solitary } & Sparse & 611 & 407 & 174 \\
& Dense & 330 & 284 & 89 \\
& Total & 941 & 691 & 263 \\
Pairs & Sparse & 94 & 85 & 32 \\
& Dense & 35 & 66 & 25 \\
& Total & 129 & 151 & 57 \\
Groups & Sparse & 18 & 22 & 11 \\
& Dense & 15 & 21 & 12 \\
Total & Total & 33 & 43 & 23 \\
\hline
\end{tabular}



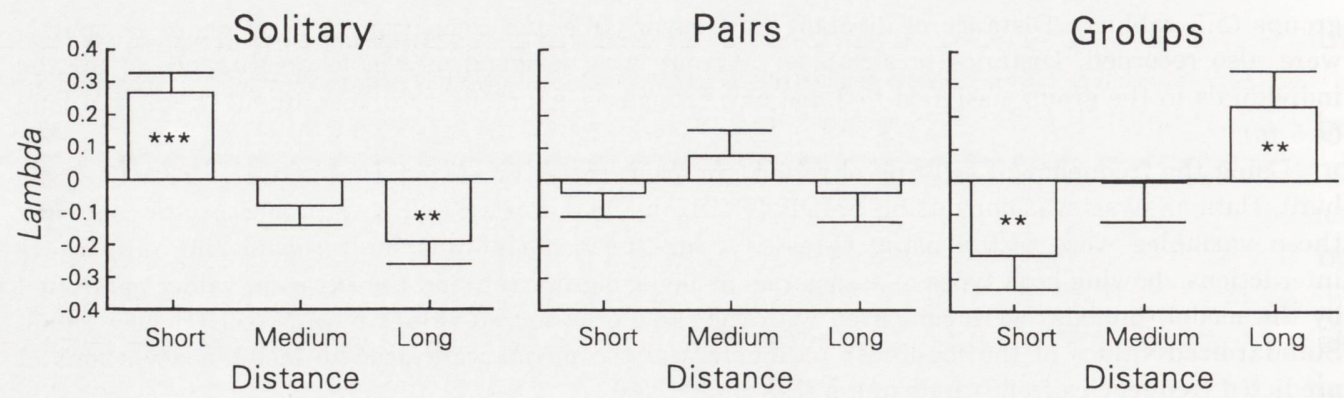

Fig. 1. Estimated values of the log-linear parameters (Lambda) and their standard errors, for the interaction between group size and rabbit-to-cover distance. Sign of the parameters indicates a greater (positive) or lower (negative) tendency of occurrence than random. $(* * *-p<0.001$, ** $p<0.01)$.

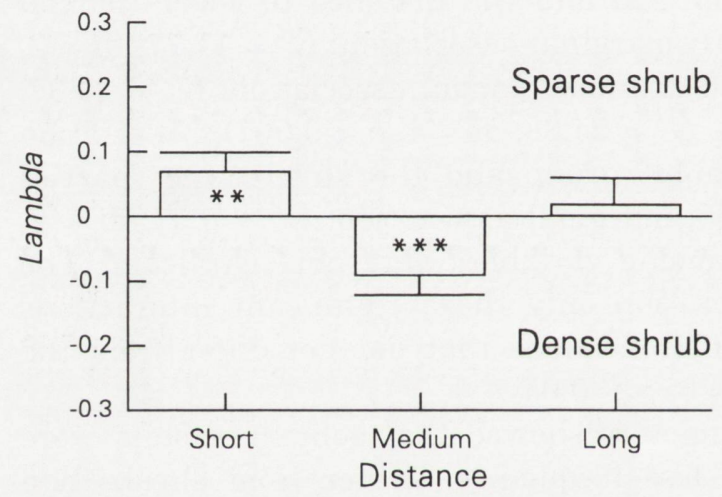

Fig. 2. Estimated values of the log-linear parameters (Lambda) and their standard errors, for the interaction between rabbit-to-cover distance and cover-type. The direction of the bar indicates if the tendency is favourable to sparse (positive) or dense (negative) cover. $(* * *-p<0.001$, $* *-p<0.01)$.

expected at random, and that rabbits in groups were found further from shrub than expected (Fig. 1). No tendencies were found in space use by rabbits observed in pairs. Rabbits remained nearer cover when the closer shrub type was sparse than when cover was dense, when they favoured the middle distances (Fig. 2). There were no significant effects of cover type on the frequency of long-distance observations.

\section{Discussion}

Grouping and use of space by rabbits is strongly influenced by sex, age, social rank, time of the day, and their role as prey (Cowan 1987, Jaksić et al. 1979, Jaksić and Soriguer 1981, Simonetti and Fuentes 1982, Moreno et al. 1996). Our data show that European rabbits respond to predation risk by remaining closer to cover when alone than when in groups. Caraco et al. (1980a), also showed that 
yellow-eyed juncos Junco phaeonotus formed larger groups when further away from cover, and these same authors (Caraco et al. 1980b) also demonstrated this grouping behaviour to be affected by the presence of a predator.

By living in groups, rabbits accrue substantial benefits, such as avoiding heat loss (through huddling in the warren), cooperative maintenance, and the construction of safety protection (eg Cowan 1987). For many species, two clear benefits of grouping are the risk dilution effect (eg Vine 1971) and the reduction in individual vigilance in its component members (eg Hoogland 1979, Lagory 1986). As indicated by Lagory (1986), alertness is positively related to vulnerability because natural selection is expected to favor an optimal (minimum necessary) level of vigilance.

In finches, escape tactics depend on the perception of the safety value of the space used (Lima 1990, Lima et al. 1987). In our study of rabbits, refuge type does not seem to affect grouping behaviour, but does influence how far the animal can venture into the open. So, when the refuge provides high protection, as happens in the dense-shrubland, rabbits take greater risks by venturing further away from cover. In contrast, in poor refuge areas, like sparse-shrubland, rabbits stay close to cover. But shrub may also provide danger for rabbits. In dense cover it would be more difficult for rabbits to detect a carnivore coming, thus rabbits would move away from thiker cover to have more time to scape.

Our results are consistent with the hypothesis that in southern Spain, at least, the formation of rabbit groups is related to defense against predation. Although our data do not indicate that group size is influenced by cover type, they demonstrate that group size is influenced by perception of risk and enables animals to exploit food further from cover. This behaviour can be considered as an adaptation in rabbits to maximise the rate of energy acquisition while minimizing predation risk.

Aknowledgements: We thank J. E. Fa, F. Alvarez, D. F. Smith and specially to J. A. Litvaitis, C. FitzGibbon, A. Lazo, J. F. Beltrán, and G. Jordán for their helpful comments. This paper is a contribution to the projects PB94-0480 (DGICYT).

\section{References}

Allier C., González-Bernáldez F., Ramírez-Díaz L. 1974. Mapa ecológico. Reserva Biológica de Doñana. División de Ciencias del CSIC Estación Biológica de Doñana, Sevilla: 1-11.

Beltrán J. F. 1991. Temporal abundance pattern of the wild rabbit in Doñana, SW Spain. Mammalia 55: 591-599.

Bertram B. 1978. Living in groups: predators and prey. [In: Behavioural ecology: an evolutionary approach. J. R. Krebs and N. B. Davies, eds]. Blackwell Scientific Publications, Oxford: 64-97.

Caraco T., Martindale S. and Pulliam H. R. 1980a. Avian time budgets and the distance to cover. Auk 97: 872-875.

Caraco T., Martindale S. and Pulliam H. R. 1980b. Avian flocking in the presence of a predator. Nature (London) 285: 400-401.

Cowan D. P. 1987. Group living in the European rabbit (Oryctolagus cuniculus): mutual benefit or resource localization? Journal of Animal Ecology 56: 779-795.

Dixon W. J. 1983. B.M.D.P. Statistical Software. University of California Press, Berkeley: 1-733. 
Edwards T. C. 1989. The ontogeny of diet selection in feeding ospreys. Ecology 70: 881-896.

Heisey D. M. 1985. Analyzing selection experiments with log-linear models. Ecology 66: 1774-1748.

Hoogland J. L. 1979. The effect of colony size on individual alertness of prairie dogs (Sciuridae: Cynomys spp.). Animal Behaviour 27: 394-407.

Jaksić F. M., Fuentes E. R. and Yáñez J. L. 1979. Spatial distribution of the old world rabbit (Oryctolagus cuniculus) in central Chile. Journal of Mammalogy 60: 207-209.

Jaksić F. M. and Soriguer R. C. 1981. Predation upon European rabbit (Oryctolagus cuniculus) in Mediterranean habitats of Chile and Spain: a comparative analysis. Journal of Animal Ecology 50: 269-281.

Kolb H. H. 1991. Use of burrows and movements of wild rabbits (Oryctolagus cuniculus) in an area of hill grazing and forestry. Journal of Applied Ecology 28: 892-905.

Kufner M. B. and Moreno S. 1989. Abundancia y amplitud de los desplazamientos de Apodemus sylvatius en cuatro biotopos de Doñana que difieren en cobertura vegetal. Doñana Acta Vertebrata 16: $179-181$.

Lagory K. E. 1986. Habitat, group size, and the behaviour of white-tailed deer. Behaviour 98: $168-179$.

Lazarus J. and Symonds M. 1992. Constrasting effects of protective and obstructive cover on avian vigilance. Animal Behaviour 43: 519-521.

Lazo A. 1992. Socioecología del ganado bovino asilvestrado de la Reserva Biológica de Doñana. Unpublished Ph D thesis, University of Sevilla, Sevilla: 1-371.

Lima S. L. 1990. Protective cover and the use of space: different strategies in finches. Oikos 58: 151-158.

Lima S. L., Wiebe K. L. and Dill L. M. 1987. Protective cover and the use of space by finches: is closer better? Oikos 50: 225-230.

Moreno S. and Villafuerte R. 1995. Traditional management of scrubland for the conservation of rabbits Oryctolagus cuniculus and their predators in Doñana National Park, Spain. Biological Conservation 73: 81-85.

Moreno S., Villafuerte R. and Delibes M. 1996. Cover is safe during the day but dangerous at night: the use of vegetation by European wild rabbits. Canadian Journal of Zoology 74: 1656-1660.

Simonetti J. A. and Fuentes E. R. 1982. Microhabitat use by European rabbits (Oryctolagus cuniculus) in central Chile: are adult and juvenile patterns the same? Oecologia (Berlin) 54: 55-57.

Vine I. 1971. Risk of visual detection and pursuit by a predator and the selective advantage of flocking behaviour. Journal of Theoretical Biology 30: 405-422.

Zeuner F. E. 1963. A history of domesticated animals. Hutchinson, London: 1-560.

Received 16 August 1996, accepted 13 January 1997. 